\section{Extinction following discrimination and the persistent discrimination effect}

\author{
KAREN GALBRAITH* \\ University of Torontot, Toronto, Ont., Canada
}

This experiment attempted to replicate the persistent discrimination (PD) effect and to compare extinction rates and patterns to stimuli which had served as positive $(\mathrm{S}+)$ or negative $(\mathrm{S}-)$ discriminanda in a discrimination test. Ten albino rats received 176 discrimination trials followed by 80 continuously reinforced trials and 36 extinction trials. The $\mathrm{PD}$ effect did not appear. Extinction rates to $S+$ and $S-$ were equivalent, with the pattern of extinction resembling that typically found following continuous rather than partial reinforcement.

Several investigators (Amsel, 1958; Skinner, 1938) have noted that early discrimination training is similar to partial reinforcement, the $S$ being rewarded on some occasions and not on others for the same instrumental response. Sirice it is well established that partial reinforcement (PRF) leads to an increased resistance to extinction as compared to continuous reinforcement (CRF), the hypothesis has been advanced that resistance to extinction of response to the positive stimulus in a discrimination should be greatèr than to a single CRF stimulus which has received an equal number of reinforcements. The evidence-for this hypothesis is equivocal. When extinction is given very early in discrimination training, before differential responding is established, resistance to extinction to the negative discriminandum (S-) is greater than to a single CRF stimulus (Peckham, 1967; Wickens \& Snide, 1955). When extinction follows formation of the discrimination, some researchers (D'Amato, Schiff, \& Jagoda, 1962; Jenkins, 1961) find increased resistance to extinction, while others (Birch, Allison, \& House, 1963; Skinner, 1938) conclude that no resistance to extinction beyond that appropriate to a $100 \%$ reinforced stimulus can be attributed to the positive stimulus of a discrimination.

There have been no experimental investigations, however, of extinction to the negative discriminandum or comparisons of extinction rates to $\mathrm{S}+$ and $\mathrm{S}-$ following formation of the discrimination. An investigation of this sort requires a phase of $\mathrm{CRF}$ to both stimuli following discrimination to equate response strength before extinction. Examination of the

*This research was supported by $\mathrm{National}$ Research Council of Canada Grant ABA-72 and National Science Foundation Grant GB-3773 to Abram Amsel and was part of a doctoral dissertation at the University of Toronto.

tNow at Lakeshore Psychiatric Hospital. Toronto. literature dealing with attempts to extinguish a discrimination, i.e., to equate response strength to $\mathrm{S}+$ and $\mathrm{S}-$, indicates one possible reason for the absence of attempts to compare extinction rates to the two discriminanda. Experiments in this area (Donovik \& Ross, 1964; Goodwin \& Lawrence, 1955; Lawrence \& Mason, 1955; Ross, 1962a, b; Stettner, 1965), with the exception of the Stettner experiment, have. demonstrated an inability tó extinguish learned discriminations. This retention of a discrimination, despite subsequent equal reinforcement of the previously positive and negative cues, has been termed the persistent discrimination (PD) effect. The initial investigations of the PD effect (Goodwin \& Lawrence, 1955; Lawrence \& Mason, 1955 ) involved learning a discrimination along another dimension during the equal reinforcement period, and the results were interpreted in terms of selective attention; i.e., since the previous cues, now irrelevant, were not "responded to," their response strengths remained unequal. The attention interpretation seems unsatisfactory, however, in view of the occurrence of the PD effect under conditions of simple presentation of the discriminanda without involvement of any other dimension during the equal Even when the original discriminanda are present during learning of a new problem and, moreover, the animal is responding correctly in terms of the new dimension, speeds to the previously negative stimulus reveal the active inhibitory properties of the old discrimination. Ross interprets that "this retention of a previous problem is not due to 'attention' to the new dimension so that the old cues are not effective but, rather, is probably due to persisting inhibition to the previously negative cue [1962b, p. 946]."

The PD effect appears whether reinforcement period (Ross, 1962a). extinction is attempted with $50 \%$ or $100 \%$ reinforcement during the equal reinforcement phase, and it appears regardless of whether or not the positive stimulus is present during reinforcement of responding to the negative stimulus (Donovik \& Ross, 1964). Overlearning of the discrimination appears to increase the PD effect (Ross, 1962a). Ross $(1962 a, b)$ concludes that while one cannot be sure that extended training on equal reinforcement schedules would not reduce or eliminate the $P D$ effect, the fact that speeds to the previous $\mathrm{S}+$ and $\mathrm{S}-$ are so clearly asymptotic over many days argues against such a possibility.

In spite of the evidence against the possibility of completely equating response strengths of $\mathrm{S}+$ and $\mathrm{S}-$ following discrimination, an attempt was made in the present experiment to compare extinction rates to stimuli which had served as positive or negative discriminanda. Discrimination was followed by a phase of CRF to both discriminanda and then extinction. A number of possible outcomes were looked for in this procedure. First, a replication of the PD effect was expected. Second, correcting for different asymptotic S+ and $S-$ speeds, the question was (1) whether extinction to S+ and Swould occur at equal rates, and (2) whether nonreinforced responding would be more characteristic of PRFor CRF-like extinction.

\section{SUBJECTS}

The Ss were 10 experimentally naive rats of the Wistar strain. They were obtained from Woodlyn Farms, Guelph, when approximately 100 days of age and were approximately 120 days old at the beginning of the experiment.

APPARATUS AND PROCEDURE

The apparatus and daily data collection procedure have been described in detail elsewhere (Amsel et al, 1966). The apparatus consisted of two parallel runways, each of which could be aligned with a common gray entry-startbox unit. The discriminanda were "split-alley" runways of the type designed by Kolesnik \& Amsel (1966) to eliminate interactions of stimulus color and schedule of reinforcement. The floor and walls of these runways were painted such that each runway was divided down the middle: for Runway BW, the left half was black and the right half white, and vice versa for Runway WB.

Following preexperimental exploration of the alleys, Ss were given discrimination training for 44 days (176 trials) and CRF for 20 days ( 80 trials). Ss received 4 trials/day -2 to $S+$ and 2 to $S-$. For half the Ss, S+ was 
Runway WB and S- was Runway BW, and vice versa for the remaining $S$. Four trial sequences $(\mathrm{S}+\mathrm{S}+\mathrm{S}-\mathrm{S}-$, $\mathrm{S}-\mathrm{S}-\mathrm{S}+\mathrm{S}+, \mathrm{S}+\mathrm{S}-\mathrm{S}-\mathrm{S}+, \mathrm{S}-\mathrm{S}+\mathrm{S}+\mathrm{S}-$ ) were randomly assigned within successive 4-day blocks. Reinforcement was a 500-mg Noyes pellet; the intraday-intertrial interval was approximately $20 \mathrm{~min}$.

Three performance measures were recorded. Starting time was measured from the opening of the startbox door to the interruption of a photobeam located 12 in. into the alley. Running time was measured from the interruption of the first beam to the interruption of a second beam located 12 in. beyond the first. Similarly, goal time was measured from the interruption of the second beam to the interruption of a third beam located 12 in. from the second and 9 in. into the goalbox ( 3 in. before the end wall of the goalbox). A microswitch on the start door and the three photobeams controlled three Standard Electric timers which recorded to the nearest $.01 \mathrm{sec}$.

Extinction was between-S. That is, rather than all Ss being extinguished to both stimuli, half were extinguished to $\mathrm{S}+$ and half to $\mathrm{S}-$. Ss received four nonreinforced trials per day to either $\mathrm{S}+$ or $\mathrm{S}$ - for 9 days ( 36 trials).

RESULTS AND DISCUSSION

Start, run, and goal entry times for each trial were summed and converted to running speed (feet per second) for each $\mathrm{S}$. Mean speeds to $\mathrm{S}+$ and $\mathrm{S}-$ during discrimination, continuous reinforcement, and extinction are shown in Fig. 1.

\section{The Persistent}

Discrimination Effect

It is clear in Fig. 1 that a period of continuous reinforcement eliminates differential responding. An analysis of variance (with the factors of stimulus and day) over the last 4 days of CRF confirmed this observation. In view of the failure of previous attempts to equate $S+$ and $S-$ speeds by this procedure, the results were unexpected. The finding is particularly surprising considering the large number of discrimination acquisition trials (176 trials) and Ross's (1962a) finding that the PD effect increases with overlearning. Comparison of the present experiment with those obtaining the PD effect reveals no apparent reason for the discrepancy. Ross ran a total of $120 \mathrm{CRF}$ trials, while the present experiment involved only 80 . The only factors which might have had an effect were the significantly greater number of discrimination trials in the present experiment (176 vs 80), possibly indicating some decrease in $S-$ aversiveness with extended acquisition, and the fact that Ross's successive

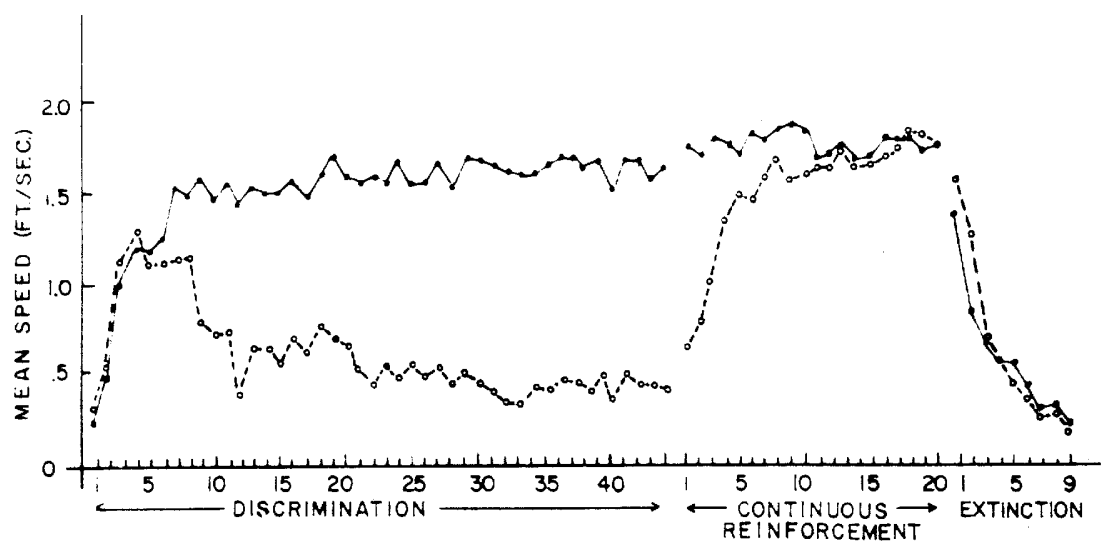

DAYS

Fig. 1. Mean speed to $S+$ and $S-$ during discrimination, continuous reinforcement, and extinction.

discrimination procedure involved forced choices in a choice apparatus. The visible blocked entrance to the positive alley possibly serves to maintain the aversiveness of $\mathrm{S}-$. This latter interpretation seems plausible in view of Stettner's (1965) results. The experiment, the only other failure to obtain the PD effect, also used separate alleys. In any case, it appears that the PD effect is not an indisruptible phenomenon and the variables involved remain to be investigated.

\section{Extinction}

Between-S extinction rates to $\mathrm{S}+$ and $S-$ are about equal, with the general pattern being more characteristic of CRF- (rapid extinction, large decrease on first extinction day, and a negatively accelerated extinction curve) than PRF-like (slower extinction, little or no decrement on first extinction curve) extinction. An analysis of variance (with the factors of group and day) of the extinction data indicated a significant effect of day but not of group, confirming the lack of differential extinction rates. The CRF-like extinction obtained in this experiment indicates strongly that, once a discrimination is formed, discrimination training is no longer analogous to partial reinforcement.

Equivalent extinction rates to $\mathrm{S}+$ and $\mathrm{S}-$ and the CRF extinction pattern can be understood within the framework of Amsel's (1962) theory of discrimination and persistence. Persistence requires the counterconditioning of the cues of anticipatory frustration $\left(r_{F}-s_{F}\right)$ to approach ( $\mathrm{S} \rightarrow \mathrm{r}_{\mathrm{F}}-\mathrm{s}_{\mathrm{F}} \rightarrow$ approach). This occurs during partial reinforcement, where, in the same stimulus situation, responses to cues from anticipatory frustration (from nonreward trials) are reinforced on rewarded trials. During the later stages of discrimination, however, where anticipatory reward and anticipatory frustration are perfectly correlated with $\mathrm{S}+$ and $\mathrm{S}-$, respectively, this never occurs. The $s_{F}$ in this situation always evokes avoidance, never becoming conditioned to approach. In extinction, therefore, regardless of the external stimulus, evocation of the avoidance response to $s_{F}$ leads to rapid extinction.

\section{REFERENCES}

AMSEL, A. The role of frustrative nonreward in non-continuous reward situations. Psychological Bulletin, 1958 $55,102-119$.

AMSEL, A. Frustrative nonreward in partial reinforcement and discrimination learning: Some recent history and a theoretical extension. Psychological Review, 1962, 69, 306-328.

AMSEL, A. RASHOTTE, M. E. \& MacKINNON, J. R. Partial reinforcement effects within-subject and between-subjects. Psychological Monographs, $1966, \quad \mathbf{8 0}(20$, Whole No. 628).

BIRCH, D., ALLISON, J. K., \& HOUSE, R. F. Extinction performance following discrimination training. Journal of Experimental Psychology, 1963, 65, 148-155.

D'AM ATO, M. R. SCHIFF, D., \& JAGODA, $H$. Resistance to extinction after varying a mounts of discriminative and nondiscriminative instrumental training. Journal of Experimental Psychology, $1962,64,526 \cdot 532$.

DONOVIK, P. J., \& ROSS, L. E. Effect of reinforcement of the negative discrimin andum in differential conditioning. Psychological Reports, 1964, 14, 107-110.

GOODWIN, W. R., \& LAWRENCE, D. H The functional independence of two discrimination habits associated with a constant stimulus situation. Journal of Comparative \& Physiological Psychology, $1955,48,437-443$.

JENKINS, H. M The effect of discrimination training on extinction. Journal of Experimental Psychology, $1961,61,111-121$.

KOLESNIK, B., \& AMSEL, A. A "split-alley" technique for equating brightness in a visual discrimination task. Psychonomic Scier.e. 1966, 187-188. LAWRENCE， D. H \& MASON,W. H. 
Systematic beharior during discrimination reversal and change tof dimensions. Journal of Comparative \& Physiological Psychology, 1955, 48, 1-7.

PECKHAM, R. H. Resistance to extinction after discrimination training as a function of amount of training and stimulus separation. Unpublished doctoral thesis, University of Toronto, 1968.

ROSS L E. The effect of equal reinforcement of the positive and negative discriminanda of a learned

\section{MOTIVATION AND EMOTION}

ADAIR, E. R. Displacements of rectal temperature modify behavioral the rmoregulation. Physiology \& Behavior, 1971, 7, 21-26.

CLARKE, S., \& TROWILL, J. A. Sniffing and motivated behavior in the rat. Physiology \& Behavior, 1971, 6, 49-52.

DAVIS, M., \& SOLLBERGER, A. Twenty-four-hour periodicity of the startle response in rats. Psychonomic Science, 1971, 25, 37-39.

FRANK, L. H. A technique for measuring thermoregulatory behavior in the fish. Behavior $\mathrm{Research}$ Methods \& Instrumentation, $1971,3,250$.

HOWARD, R. L., \& MEYER, D. R. Motivational control of retrograde amnesia in rats: $A$ replication and extension. Journal of Comparative \& Physiological Psychology, 1971, 74, 37-40.

LEE, C. T., \& ESTEP, D. The developmental aspect of marking and nesting behaviors in Mongolian gerbils (Meriones unguiculatus). Psychonomic Science, 1971, 22, 312-313.

Activity and Exploratory Behavior

FIBIGER, H. C., \& CAMPBELL, B. A. Effect of adrenal demedullation on starvation-induced behavioral arousal. Physiology \& Behavior, 1971, 6, 403-405.

MORLOCK, G. W., FRANK, L. H., \& MEYER, M. E. Activity in chicks as a function of visual loss and within-test duration. Psychonomic Science, 1971, 23, 200.

OWINGS, D. H., \& LOCKARD, R. B. Different nocturnal activity patterns of Peromyscus californicus and Peromyscus eremicus in lunar lighting. Psychonomic Science, $1971,22,63-64$

RANDOLPH, $M$. Role of light and circadian rhythms in the nocturnal discrimination. Journal of Comparative \& Physiological Psychology, 1962a, 55. 260-266.

ROSS, L. E. The response to previous discriminanda during the learning of a new problem. Journal of Comparative \& Physiological Psychology, 1962b, 55, Physiologica
$944-946$.

944-946.. F The behavior of organisms.

New York: Appleton-Century-Crofts, 1938

STETTNER, L. J. Effect of prior reversal and elimination of inhibition on the persistence of a discrimination despite subsequent equal reinforcement of the discriminanda. Journal of Comparative \& Physiological Psychology, 1965, 60, 262-264.

WICKENS, D. D.. \& SNIDE, J. D. The influence of nonreinforcement of a component of a complex stimulus on resistance to extinction of the complex itself. Journal of Experimental Psychology, 1955, 49, 257-259. behavior of Galago crassicaudatus. Journal of Comparative \& Physiological Psychology, 1971, 74, 115-122.

\section{Locomotor Activity}

BOLAND, B. D., \& DEWSBURY, D. A. Characteristics of sleep following sexual activity and wheel running in male rats. Physiology \& Behavior, $1971,6,145-149$.

COLLIER, G., \& HIRSCH, E. Reinforcing properties of spontaneous activity in the rat. Journal of Comparative \& Physiological Psychology, 1971, 77, 155-160.

GOODRICK, C. L. Direct observation and automated scoring of the activity of active and inactive inbred mouse strains. Behavior Research Methods \& Instrumentation, 1971, $3,255-256$.

HETU, R. Deprivation-feeding cycle and locomotor activity of the albino rat in a complex maze. Psychological Record, 1971, 21, 125-130.

LESHNER, A. I. The adrenals and the regulatory nature of running wheel activity. Physiology \& Behavior, 1971, 6, 551-558.

MILLS, P. D., CULLEN, J. C., McKENZIE, J. R., SATHER, B. R. \& KAMBACK, M. C. Running-wheel activity of insulin-injected rats. Psychological Reports, 1971, 28, 415-420.

MOORCROFT, W. H., LYTLE, L. D., \& CAMPBELL, B. A. Ontogeny of starvation-induced behavioral arousal in the rat. Journal of Comparative \& Physiological Psychology, 1971, 75, 59-67.

MORLOCK, G. W., FRANK, L. H., \& MEYER, M. E. Activity in chicks as a function of visual loss and within-test duration. Psychonomic Science, 1971, 23, 200.

QUAY, W. B. Effects of cutting nervi conarii and tentorium cerebelli on pineal composition and activity shifting following reversal of photoperiod. Physiology \& Behavior, 1971, 6, 681-688.

S C H R E I B E R, R . A . , \& SCHLESINGER， K. Circadian rhythms and seizure susceptibility: Relation to 5-hydroxytryptamine and norepinephrine in brain. Physiology \& Behavior, 1971, 6, 635-640.

TARPY, R. M. Effects of food deprivation on spontaneous activity and blood glucose. Psychological Reports, 1971, 28, 463-469.

WOODS, D. J., \& ROUTTENBERG, A. "Self-starvation" in activity wheels: Developmental and chlorpromazine interactions. Journal of Comparative \& Physiological Psychology, 1971, 76, 84-93.

\section{Exploratory Behavior}

CLARK, G., KOESTER, A. G., \& PEARSON, D. W. Exploratory behavior in chronic disulfoton poisoning in mice. Psychopharmacologia (Berlin), 1971, 20, 169-171.

GOODRICK, C. L. Variables affecting free exploration responses of male and female Wistar rats as a function of age. Developmental Psychology, $1971,4,440-446$.

MEANS, L. W., LEANDER, J. D., \& ISAACSON, R. L. The effects of hippocampectomy on alternation behavior and response to novelty. Physiology \& Behavior, 1971, 6, 17-22.

MORLOCK, G. W., ERSPAMER, R. T., \& MEYER, M. E. The effect of arousal on exploration in the rat. Psychonomic Science, 1971, 25, 43-44.

WILZ, K. J., \& BOLTON, R. L. Exploratory behavior in response to the spatial rearrangement of familiar stimuli. Psychonomic Science, 1971, 24, 117-118. 